\title{
Representativeness, legitimacy and power in public involvement in health- care management
}

\author{
Graham P. Martin
}

\begin{abstract}
Public participation in health-service management is an increasingly prominent policy internationally. Frequently, though, academic studies have found it marginalized by health professionals who, keen to retain control over decision-making, undermine the legitimacy of involved members of the public, in particular by questioning their representativeness. This paper examines this negotiation of representative legitimacy between staff and involved users by drawing on a qualitative study of service-user involvement in pilot cancer-genetics services recently introduced in England, using interviews, participant observation and documentary analysis. In contrast to the findings of much of the literature, health professionals identified some degree of representative legitimacy in the contributions made by users. However, the ways in which staff and users constructed representativeness diverged significantly. Where staff valued the identities of users as biomedical and lay subjects, users themselves described the legitimacy of their contribution in more expansive terms of knowledge and citizenship.
\end{abstract}

My analysis seeks to show how disputes over representativeness relate not just to a struggle for power according to contrasting group interests, but also to a substantive divergence in understanding of the nature of representativeness in the context of state-orchestrated efforts to increase public participation. This divergence might suggest problems with the enactment of such aspirations in practice; alternatively, however, contestation of representative legitimacy might be understood as reflecting ambiguities in policy-level objectives for participation, which secure implementation by accommodating the divergent constructions of those charged with putting initiatives into practice.

Published in: $\quad$ Social Science \& Medicine 67(11): 1757-1765

http://www.elsevier.com/locate/socscimed

http://dx.doi.org/doi:10.1016/j.socscimed.2008.09.024

\section{Introduction}

As in other countries, the health-care system in Britain has been subject to an increasing drive to engage on a collective level with its public, variously defined as patients, service users, communities, taxpayers and citizens. However, public participation is limited by various constraints, including a widely observed reluctance on the part of health professionals and managers to engage with the public and put into practice the outputs of public-involvement processes (Milewa, 1997; Rowe \& Shepherd, 2002; Crawford, Rutter \& Thelwall, 2003). By seeking to undermine the legitimacy of those involved (Beresford \& Campbell, 1994), controlling the course of meetings (Williams, 2004), or selectively implementing the suggestions of publicparticipation processes (Milewa, Valentine \& Calnan, 1999), professionals and managers are seen to retain control over decision-making processes, or manipulate public participation to ensure that it advances their own interests (Harrison \& Mort, 1998; Milewa et al., 1999; Tritter, Barley, Daykin, Evans, McNeill, Rimmer et al., 2003). In order to further their own influence, involved members of the public too are forced to defend their own legitimacy, and so are drawn into a 
complex discursive game with staff, as each group seeks to assert or undermine the legitimacy of participants (Contandriopoulos, 2004).

This paper seeks to further understanding of this process by drawing on a qualitative study of a particular example of public participation-service-user involvement in cancer-genetics services - and the way in which the bounds of legitimacy of this process are contested by those involved. In particular, the study considers how the 'representativeness' (or otherwise) of the involved users is constructed by these parties. Past research has noted the tendency of professional staff to question the representativeness of involved members of the public as one means of retaining control over the process (Crawford et al., 2003). The data I present below affirm the importance of the negotiation of representativeness in determining the outcome of public-participation initiatives. Rather than being used to legitimize or delegitimize public participants, though, divergent notions of representativeness are deployed in pursuit of differing roles for public participation that reflect different ideas about its function, and the relationship between state governance, professional expertise and the public. This might be understood as the distortion of participation policy by those charged with implementing it. However, each divergent interpretation finds justification in the ambiguous and multiple rationales for public participation embodied in policy. Rather than the distortion of a clear policy mandate, then, I argue that in common with certain other recent reforms to the British health service, this is a matter of broad, inclusive central guidance which secures implementation, but means that outcomes will always be contingent on local interpretation and negotiation.

\section{Public participation and the struggle for legitimacy}

The academic literature notes the importance of representativeness in public-participation initiatives. Frequently, public involvement relies on self-selection or the selection of 'appropriate' or acquiescent individuals by health professionals, resulting in exclusion and elitism, and reliance on "the same traditional middle-class cross-section of citizenry to represent the interests of all" (Church, Saunders, Wanke, Pong, Spooner \& Dorgan, 2002, p.17). Health professionals and managers often share these concerns, and as Crawford et al. (2003, p.46) note, "concerns of service providers about the representativeness of service users who contribute to [user involvement] are a frequently cited impediment." Finding a representative sample, however, is not straightforward, given the nebulousness of the concept of representativeness itself. In their study of various public-participation initiatives in local government and health, for example, Barnes, Newman and Sullivan (2007) found that where officials tended to hold relatively conservative notions of representativeness, informed by the norms of representative democracy or by statistical notions of demographic correspondence between representatives and represented, these were often challenged by the rather different notions of representativeness and legitimacy held by public participants. Members of a community health forum saw themselves as representative of others on account of their local connections and willingness to take on the duty of participation, for example, while a youth group saw its shared history of action as providing legitimacy. "These different claims were not necessarily sources of conflict, but could become so if the rules governing the participation initiative privileged one set of representative claims over others" (Barnes et al., 2007, p.197).

Substantive differences of view about the nature of representativeness needed to realize the purpose of public participation are, furthermore, often accompanied by more instrumental efforts by staff to marginalize public participation. Frequently, professional challenges to representativeness and legitimacy are seen in the literature as ploys to defend existing power relationships and control over decision-making processes in the face of the new 'challenge' from public involvement (Beresford \& Campbell, 1994; Bowl, 1996; Barnes, 1999; Sanderson, 1999; Williams, 2004). Thus "any individual claim to belong to or represent the public will face some opposition from other categories of actors" (Contandriopoulos, Denis \& Langley, 2004, p.1590). Bowl (1996), for example, found that pressure on service-user representatives from mental-health 
professionals to justify their representativeness led to some withdrawing altogether. "It is critical," he concluded, "to the future of user involvement that concern about representativeness should not be used to prevent its extension" (Bowl, 1996, p.300).

In resisting a shift in control in health-service governance away from them, staff may also seek to channel public involvement in a way that corresponds to their professional interests (Harrison \& Mort, 1998; Contandriopoulos et al., 2004; Daykin, Sanidas, Tritter, Rimmer \& Evans, 2004). Harrison and Mort (1998) characterize public and user involvement as a 'technology of legitimation' to which particular professional groups accord no intrinsic representative legitimacy, but which they use in advancing their own ambitions over those of other groups. Daykin et al. (2004, p.292), meanwhile, discuss how physicians tend to prioritize individualized categories of disease, "resisting notions of users as a group yet at the same time rejecting individual users as 'unrepresentative'." Barnes (1999, p.79) observes a similarly curious double standard among mental-health professionals, who dismiss organized groups of service users as unrepresentative 'pressure groups' rather than the voice of collective experience. But

the irony of this is that hitherto unorganized service users or citizens who become participants in health service decision-making can also be berated for expressing personal views and reflecting personal experiences rather than taking the wider view and reflecting, for example, on the needs of populations.

For Beresford and Campbell (1994), this signifies a particularly acute hypocrisy: professionals generate structures that make impossible certain forms of representativeness-for example the designation of one place on a committee for a public 'representative' selected by professionalsand then berate those involved for their lack of representativeness.

Much of the literature, then, finds challenges to representativeness associated more with a defence of professional power or the advancement of professional interests than with a genuine concern about the constitution of involved publics. This might be seen in terms of established professional constructions of disease and of the 'proper' professional-patient relationship, or as rather a more basic desire to retain control over decision-making processes in the face of a new set of stakeholders who have been given some credence, legitimacy and power by policymakers. Either way, as Crawford et al. (2003, p.46) conclude from their systematic review of user involvement in change management in health, "it is difficult to escape the conclusion that the aim of such challenges [to representativeness] is to undermine users of services."

Confronted with these kinds of challenges to their legitimacy, involved members of the public respond by seeking to justify their representativeness (Barnes, Newman, Knops \& Sullivan, 2003; Contandriopoulos, 2004; Barnes et al., 2007). However, given the multiplicity of meanings attached to the notion, articulating a representative legitimacy that is also acceptable to professionals is not an easy task. Davies, Wetherell and Barnett (2006), for example, highlight how even carefully constituted groups can be subjected to charges of unrepresentativeness if they make suggestions out of kilter with those of professionals. Consequently, representativeness may become subject to a complex justificatory negotiation between the parties involved. An example of this is Beresford and Campbell's (1994, p.317) critique of professional notions of representativeness in user involvement in the field of disability, which are based, they claim, on unsubstantiated presumptions about the difference between the individuals involved and the wider population:

We become 'unrepresentative' in ways some service providers do not want. We become confident, experienced, informed and effective. At the same time, because getting involved is not something that most people are encouraged or have the chance to do, the mere fact of being involved may be seen as making us 'unrepresentative'.

Thus for Beresford and Campbell (1994), any disparity between the 'active' involved individual and the 'passive' wider public is down to structural impediments rather than any inherent unrepresentativeness. Claims to the contrary, they suggest, might be seen as a matter of selfinterested professional resistance. 
Involved publics in various fields thus find themselves engaged in struggles for legitimacy that often revolve around conflicting constructions of representativeness. In the absence of any foundational, agreed notion of representativeness, the negotiation of legitimacy may become something of a discursive struggle, the outcome of which rests on the effectiveness with which those involved can claim legitimacy for their notion of representativeness:

The production and efficacy of representation rests on symbolic operations that grant the representative its legitimacy. In other words, legitimacy is not so much granted directly by formal or descriptive representation as by the (subjective) perception of 'representativeness'. [...] The political efficacy of public participation ultimately rests upon symbolic struggles to appropriate the intrinsic legitimacy of the public." (Contandriopoulos, 2004, pp.327-8)

Following Contandriopoulos's argument, the negotiation of representativeness is inevitably a discursive one, resting on claims to speak for 'the public'. Professionals and involved members of the public alike, then, are implicated in this struggle to affirm or discredit claims to speak for some wider public, upon which legitimacy—and therefore power-rests.

To summarize: in much of the academic literature, professional challenges to the legitimacy of public participation on the basis of the unrepresentativeness of those involved are characterized as a defensive means of retaining control over decision-making processes and maintaining professional constructions of illness and the patient-professional relationship. Claims to representativeness consequently become a crucial point of negotiation between the parties involved, since they are often central to the legitimacy (and thus efficacy) of public involvement. In the absence of any clear and incontrovertible form of representativeness, neither involved publics nor professionals can make foundational claims to legitimacy, and so the negotiation becomes a largely symbolic one. The outcome rests on the relative success of involved members of the public in establishing themselves as representative, and of professionals in disclaiming this representativeness and thereby resisting the wishes of involved publics.

Exactly how such negotiations play out in practice, however, will differ according to a number of variables, and Contandriopoulos (2004) and Barnes et al. (2007) both find considerable divergences among their case studies of participation. The field in which participation is proposed, the nature of the public to be represented, the rationale for participation, etc.: each of these affects the character of the legitimacy claims and the course of their negotiation. For example, Barnes et al. (2007) find that concerns about representativeness were considerably more prominent among staff involved in public-participation initiatives designed to elicit the views of service users and residents of particular neighbourhoods than initiatives aimed at engaging with particular social issues, where public participants' knowledge was seen as an alternative justification. The contextual determinants of the negotiation of legitimacy are crucial, and "further research is needed to identify the specific factors activated in and through processes of public deliberation" (Barnes et al., 2003, p.277) that will influence such negotiations.

The remainder of this paper therefore presents analysis of a public-participation initiative in one distinctive empirical field. On the basis of the analysis of the literature above, I consider the views of staff and public participants in order to examine

- the understanding of the notion of representativeness held by the different parties: following Barnes (cited in Crawford et al., 2003), is it understood in terms of electoral process, statistical reflection of the demographic profile of the group to be represented, 'typicality' of those represented, or in some other way?

- how far these notions of representativeness are compatible or in conflict with one another, in terms of the remit for public participation they imply, and the way in which they are drawn upon symbolically (Contandriopoulos, 2004) in enacting the process of public participation.

- more expansively, what this tells us about the views of the parties involved about the role of public participation in contemporary health-service governance, and on the proper 
relationship between professional staff and the public they serve.

As we shall see, the negotiation of representativeness in this field followed a somewhat different course from that suggested by the literature. Whilst the particularities of the case were important in this divergence, I argue that the findings also emphasise the need to account for the substantive, as well as instrumental, causes of conflicts over the nature of representative legitimacy, and how these relate to the broad and ambiguous functions ascribed to public participation in contemporary policy.

\section{Empirical field and methods}

The findings presented here derive from qualitative research on service-user involvement in seven pilot cancer-genetics services, which was part of a wider evaluation of a programme of genetics pilots in the English National Health Service (NHS) funded following the genetics white paper (Secretary of State for Health, 2003). The cancer-genetics pilots, which were cofunded by Macmillan Cancer Support and the Department of Health (DH), were charged with the task of implementing a rationalized care pathway for people at possible risk of inherited cancer, known as the 'Kenilworth model' (see Martin et al., 2007).

In common with pilots in the wider programme, the cancer-genetics pilots were required by their sponsors to include plans for user involvement in their work, as a condition of funding. In contrast to the other pilots, though, which were funded by the $\mathrm{DH}$ alone, Macmillan - a thirdsector organization with a traditionally medical orientation and membership, but with an increasingly prominent focus on the voice of cancer patients and carers-was insistent that these plans be enacted. Through a combination of guidance for staff, support for users and monitoring of progress, Macmillan ensured that user involvement took place in each pilot. Consequently, where user involvement barely existed in the other pilots, it was present in all seven of the cancer-genetics projects. With a view to ensuring that user involvement was central to pilots' work, Macmillan required that their reports include "evidence of involvement in design and review of the new service" and "evidence of influence by people affected by cancer in the pilot service" (Macmillan document entitled 'Format for pilot project final reports' circulated to pilots). However, it was also deliberately non-prescriptive about the precise form that user involvement should take, and so there were notable differences in the commitment to user involvement, the role it was given, and its degree of influence among the seven pilots.

Research on user involvement in the pilots took several forms. In-depth interviews with 12 involved users (seven interviewed twice), five staff responsible for supporting and developing user involvement through Macmillan, and 32 pilot staff were completed. Pilot staff were predominantly clinical (physicians, nurses and genetic counsellors), with some non-clinical administrative staff. There were some differences between the views expressed by these professional groups, but for the purpose of this paper, the common features of their views are highlighted as they contrast with those of involved users. A second form was participant observation at some 39 meetings and events at which user involvement occurred over 30 months, including 21 meetings in six of the pilot sites and 18 national meetings convened by Macmillan to support the pilot programme collectively or user involvement specifically. This permitted observation of the negotiation of user involvement as it occurred through time. Thirdly, analysis of pilot proposals, interim reports and evaluations, and the documents on user involvement produced by Macmillan, enabled an understanding of the aims anticipated for user involvement, and the practical issues faced when attempting to realize these, again with a longitudinal dimension.

Interviews, which lasted between 40 minutes and $3 \frac{1}{2}$ hours, were audio-recorded and fully transcribed. They included questions about various aspects of public participation, including specific questions about representativeness, alongside more general questions about the legitimacy, role and remit of user involvement. Analysis was conducted with the assistance of NVivo 7. I read each transcript, set of notes and document several times, generating and coding 
themes iteratively according to both issues identified in the literature, and features of the data that became apparent more inductively. For example, 'representativeness' was included as a category on the basis of the extant literature, and sections of interviews and observational notes pertaining to it were coded accordingly. Other categories, such as the nature of the 'lay' or 'biomedicalized' user identity considered below, were constructed more inductively from the data themselves. Data were then considered on a within-category basis in relation to the analytical framework presented at the end of the previous section.

\section{Results}

\section{Selection of involved users}

The mandation of user involvement by Macmillan meant that recruiting involved users was an important early task for pilot professionals as they set up services. However, an immediate problem for them was that, on account of the projects' status as new pilots, by definition no 'users' in the narrowest sense existed. It fell upon project staff to decide how they wished to deal with this issue and recruit for their user groups. Several described the difficulties they had faced attempting to reconcile the need for participation of any sort with a desire to recruit individuals who might provide a relevant contribution. Given the need to populate their user groups and show that they were indeed practising user involvement in some form, staff tried various means of attracting users, including asking colleagues for suggestions, contacting previous patients, asking early users of the new services, and approaching local voluntary groups and existing patient- and public-involvement groups.

Consequently, the identities of the involved users were heterogeneous. Whilst most had some experience of cancer and/or genetic risk, few had used the pilot services themselves, and indeed some had no direct personal experience of cancer. They were also socioeconomically diverse, though the majority had certain characteristics in common. Most were over 40, retired (either due to age or for medical reasons), or did not work for other reasons, and had either put themselves forward or had been approached by staff who saw them as suitable candidates. Accordingly, there was acknowledgement among users that they were not altogether 'representative' in any narrow sense, and many described at national user meetings how they had implored staff in the pilots to attempt to recruit 'real' users too.

Involved users were also aware that their very status, as people who had chosen to participate, distinguished them from the wider population: they saw themselves as more engaged, active, forthright than the 'average person'. However, for the involved users, and for Macmillan, this particularity and lack of representativeness narrowly defined were not things that necessarily impeded the ability to represent the wider constituencies of patients and publics of the services. Rather, if anything, the particular intersections of skills and experiences embodied in the users were an asset in this representational work, as one Macmillan respondent explained in describing the users who attended the national meetings:

"Some of them had a family history of cancer, so that was relevant. Others have a history of caring for someone who died of cancer, so that was relevant. So all of these things meant that they weren't just Jo Bloggs off the street. They were people with an interest, and a history which was relevant. And I think what also began to emerge just from hearing people talk was - there are certain preconceptions about service-user representatives. One preconception would be that they have a hobby horse. [...] But [...] I think they were all really doing their best to somehow represent service users, and not just-you know, [Harry] doesn't just talk about bowel cancer. The breast cancer patients don't just talk about breast cancer. [...] Carers don't just bang on about the needs of carers. I think they do a pretty good job, actually, of representing the views of service users."

By virtue, then, of their interestedness, and the diversity and particularity of their experiences and consequently their knowledge, the involved users saw themselves as having a certain 
representative role to perform that belied their lack of representativeness in a narrow sense.

\section{Professionals' constructions of representativeness and legitimacy}

Pilot staff, too, were conscious of the unviability of formal or statistical claims to representativeness of involved users. However, they were also quick to recognize the structural impediments to this, and reflexive enough to acknowledge their own part in this as the ones who had set up user involvement in their projects.

Furthermore, staff too did not see the lack of representativeness narrowly defined as necessarily impeding the representative role of involved service users. Rather, to the extent that users spoke to issues that were universally relevant to the broader constituency of patients and the wider public, staff did see them as having a representative validity of sorts. One staff member sought to outline the scope of this legitimacy:

Respondent: Each of [the users] who attended were very clear about who they were as individuals and their backgrounds: as I say, a lawyer, advertiser, and a project manager. So they were very much expressing their views and their experience. I don't think they were representing the views of users generally, because-by that I mean the makeup of users, I imagine, is so varied that it would be very difficult to get one perspective on that.

Interviewer: Yeah, one typical user who reflects all those things.

Respondent: Indeed. But the issues that they were addressing, in terms of accessibility, information, the clarity of communication, those were clearly generic.

(Genetic counsellor, site D)

Particularity of background and experience meant for this staff member that involved users were explicitly not representative. Yet notwithstanding this, their ability to speak to "generic" issues, where views were not dependent upon particularities of class or motivation or knowledge, gave their input a wider validity.

Other staff offered similar views on the potentials and limits of users' representativeness. In particular, professionals identified two notable contributions of involved users where representative legitimacy was possible despite users' particularities. Firstly, user involvement could offer a source of perspectives on the patient experience: what was satisfying, what could be better, how things might be changed and so on. So for example:

"It's important to have people who have been through the service, 'cause they're commenting on how we've contacted them, how they knew about this service, how they were treated at their appointments, letters and follow-up and that sort of thing."

(Project administrator, site B) Secondly, staff highlighted the potential contribution of user involvement to understanding laypeople's perspectives. So, for example, user involvement was something which could help professionals phrase their communication and information provision in a way that would be amenable to 'laypeople': informative without provoking excessive anxiety; comprehensible without being patronizing:

"[Emma] looked at the information that was available so we could see whether we need to devise our own information or use existing information, and we went for the Cancer Backup stuff, so she was involved with that. She has been involved with different letters that are going to be put on the software [a system to compose letters to patients, detailing their risk status and possible options]. [...] So she has been looking at those sort of things from a patient view."

(Nurse, site E)

"When you're coming from a nursing professional background, you instantly forget that people aren't perhaps so able to understand some of the jargon that you use, whereas [the involved users] could swap those sentences round and make it easy to read for people. And definitely, what they achieved was really good, easy-to-read, literature. [...] We 
[professional staff] designed the leaflets for the GPs and health professionals. That was fine, we could write that no problem. But it was difficult to find the right level for the general public. And they [involved users] got it spot on."

(Nurse, site F)

Thus it was in their status as patients and/or as laypeople that health professionals saw the particular value and legitimacy of involved users. When it came to the input of user involvement into decisions about the planning, management and evaluation of the services, most health professionals saw the legitimate scope and limit of this contribution as determined by the extent to which involved users fitted these notions of status as patients and laypeople: how 'typical' they were of these categories of public. Representativeness for staff, then, came down to a question of how far involved users' identities conformed to this constrained, biomedicalized or lay identity as individuals defined by their patienthood and/or lack of clinical-professional knowledge. This was evident too in the pilots' evaluation reports. The section on user involvement from site B's report, quoted in its entirety below, was typical, if slightly briefer than most others:

"Service users were recruited through the Clinical Genetics Department and the community clinics. Service users' ideas were sought about the location and promotion of the clinics and the design and content of all the publicity and patient letters.

"A patient satisfaction survey was devised with the help of the Service User Group and distributed to everyone attending the clinic over a 6 month period."

This view of user involvement, then, endowed it with legitimacy derived from a certain kind of representativeness-but this construction also tended to limit the scope of legitimacy to particular issues where involved users were qualified to comment on the basis of their patienthood or laity. Moreover, this predominant professional account of legitimacy constructed user involvement itself as a source of data that might help to answer certain questions as defined by health professionals (around patient satisfaction, information provision and so on) rather than as a more active, open-ended and self-defining contribution.

\section{Users' constructions of representativeness and legitimacy}

Involved users were also pleased to offer their clinical experience and the different perspective they held from clinical professionals. However, they constructed these contributions rather differently. For users, then, this was not an inert resource, a 'raw data set' for clinical professionals to act upon. Rather, it was an epistemically distinct set of insights that was different from, but not subordinate to, the clinical perspective. Thus even in describing the kind of contribution that both health professionals and involved users saw as legitimate, users tended much more to emphasise the role of their own agency and reflection in ensuring its validity:

"Being involved early on with the literature, that's made a difference. Just tweaking it really, because I thought, 'If I'm going to read something, if I was picking up something for the first time, how would I want it to be worded?' I wouldn't want it to be patronizing and I wouldn't want it to assume that I was uneducated, but then I also have to think, 'Well not everybody uses the same language that I use.' So it was important to get it so that it was as sensitive as it possibly could be, making sure that it was readable for most people."

(Involved user 1, site G)

Here, then, a contribution to information provision was constructed not as the input of a moreor-less 'typical' user whose views must be balanced by the health professional and given credence according to the degree to which they are 'representative' or 'generic'. Rather, this process of scrutiny and analysis was something best done reflexively by the involved user herself, better placed to carry out this interpretive work than the health professional.

More generally, for reasons already noted, involved users tended to see the potential scope of their contribution in much broader terms than pilot staff, with atypicality an aid, not an impediment, to representational legitimacy. If health professionals reduced users' contributions to their biomedical or lay identity, then for users they were missing out on a swathe of useful 
contributions that user involvement might present. For involved users, the most potent aspects of their contribution derived from the very professionality of their perspectives, not from the constrained perspective of patient or layperson:

"You don't become a different species just because you are [a cancer patient], and there's still all the same things that you know: you work in the same manner, your head works in the same manner, it's just on a different subject. [...] The involvement of everybody is so important—it's using people's skills. I think there's a lot out there to be tapped, [...] besides the information, and besides not being told what you want, [...] I think there's a lot of skills out there they can tap."

(Involved user 2, site G)

Experiences and skills were for involved users a source of legitimacy in themselves, not something which 'interfered' with the ability of users to speak to 'generic' issues as patients and laypeople. Thus the claims of involved users to legitimacy went both beyond professional constructions, and beyond the initial rationale for user involvement defined by the programme's sponsors, to secure the "influence of people affected by cancer":

"On the patient and carers group, we've got a good mix of people with professional backgrounds, so some of us do know how things work. We might not know how the NHS works, but I mean we have an ex-bank manager. He has definitely sorted how the funding's going. We all have skills to bring to this, and this is what gets to me. [...] I think it's just having a clue about where people come from."

(Involved user, site A) From the users' perspective, health professionals were characterizing users' input in terms of its alterity: as a biomedicalized or lay 'other' to clinical professional expertise. In so doing, they were constraining the potential of user involvement by limiting it to an unnecessarily narrow conception of representative legitimacy, and missing out on the range of skilled contributions that users could make by drawing on the knowledge they derived from wider life experiences, including professional knowledge.

This was a point of deliberation at the national 'Pilots Together' events, which brought staff and involved users from all seven sites together to exchange ideas and spread good practice. At these, staff put forward a vision of user involvement in line with that outlined in the previous subsection. Involved users responded by highlighting the skills, connections and commonalities they had with various wider constituencies which, they felt, enabled them to give an input that melded distinctiveness with representational validity. At one early meeting, a clinician from one site asked whether it might not be better for patients themselves to be involved, rather than "committee members." Macmillan staff and users responded that most involved users had in some sense been real users too, and were mediating the perspectives of others through their work. One involved user retorted quite angrily: "We are users; we represent more people than ourselves."

At national meetings convened by Macmillan for involved users only, a similar collective construction of representativeness emerged. The users saw their particularity of skills, determination and motivation as being what enabled them to speak for a disempowered or unmotivated wider population. During a conversation on the subject at one such meeting, one user observed:

"We are self-selecting, in that we've been through it, gone through the emotions and still want to make a difference, rather than thinking, 'I don't want to go through that again,' and putting it to the back of our minds. We're all serious-minded people, we want to make a difference and that comes through: we're here to do a job."

In this construction, the wider public had a common political interest that could be represented through involved users as the ones endowed with the agency or tenacity to work on its behalf. As another user summarized later in this conversation: "I'm fighting for those people, their voice: I am their voice in getting the service we deserve." 
However, whilst these national meetings offered involved users a discursive stage on which to put forward their construction of user involvement, users found influence within the pilots more challenging. Users found themselves isolated in professionally dominated meetings, and, furthermore, attempting to enact their vision of a more expansive role for user involvement at precisely the point at which agenda were most narrowly focused on technical and administrative matters (project- and steering-group meetings). Consequently, in determining a role for user influence 'on the ground', it was the professional construction of representativeness that tended to structure involvement.

\section{Discussion}

The divergence of ideas about the legitimate role and contribution of user involvement between staff and users is evident in the previous section. However, despite the lack of electoral or statistical representativeness of the users involved, staff did not use this to undermine their legitimacy. Rather, professionals ascribed a certain degree of representative legitimacy to involved users, on the basis of their laity (vis-à-vis clinical expertise) and their patienthood. For staff, this enabled users to speak to certain issues of universal relevance to the wider population of patients and the public, such as communication and patient satisfaction. In these restricted domains, involved users were seen as sufficiently 'typical' to give a perspective that was more widely valid, with which their particularity of identity did not interfere. Involved users, meanwhile, saw both representative legitimacy for their role, and a wider, skills-based input, which enhanced rather than impeding the ability to represent wider publics. For them, health professionals' understanding of user involvement was too restrictive, constructing their views as no more than the deficient 'other' of clinical professional expertise. They saw their wider experiences as permitting a more nuanced, technocratically useful contribution, as well as enabling them to speak effectively for the wider public, constructed as citizens with a collective interest beyond bounded questions of patient satisfaction and information provision.

There is a degree of divergence in the empirical narrative presented here from that prominent in the literature. Rather than contesting the legitimacy of the involved users, the construction of user involvement articulated by the various staff tended to frame their legitimacy, constituting its boundaries to fit with professionally acceptable terms of reference. This contrasts to some extent with the view that professional challenges to representative legitimacy are primarily about the retention of power in the face of user involvement: that "people's representativeness assumes importance if what they say threatens or challenges the status quo. This suggests that the function the argument serves is to neutralise and exclude" (Beresford \& Campbell, 1994, p.318; cf. Bowl, 1996; Crawford et al., 2003; Contandriopoulos, 2004). The findings here also seem to contrast with previous research which has found the acceptance of legitimacy by professionals and managers to be a means of pursuing strategic interests: "where a particular set of officials happens to be in agreement with a user group but in disagreement with other officials [...] it makes sense to build up the legitimacy accorded to the user group" (Harrison \& Mort, 1998, p.66; cf. Daykin et al., 2004). The concerns about representativeness held by professionals considered above seem considerably more substantive in nature, relating to the degree of legitimacy that could be accorded on the basis of 'typicality' in the absence of other forms of representativeness. This is not to say that they were not influenced also by a degree of instrumentality, and certainly their views seemed informed by the expectation of a relatively conservative power relationship between staff and users. However, the concerns could not be reduced to a logic of power retention or the pursuit of professional interests.

The particularities of the case in question may partly illuminate the reasons for this divergence. In common with many user- and public-participation initiatives (for recent examples, see Rutter, Manley, Weaver, Crawford \& Fulop, 2004; Fudge, Wolfe \& McKevitt, 2008), the brief for user involvement in this field - to secure "the influence of people affected by cancer"-was a broad one, subject to interpretation by the parties involved. However, the work of one of the 
sponsors, Macmillan, to ensure that user involvement in some form was put into practice in the seven sites, meant that pilots needed to demonstrate that user involvement was being granted legitimacy and influence, not simply being marginalized. For staff, legitimate influence was about the narrow inputs noted above; for involved users, it extended to a more wideranging input, that included technocratic contributions and the role of representing a wider (though unclearly defined), disempowered public. Both constructions of the legitimate role for user involvement thus diverged to some extent from the loose, original remit as defined by the sponsors, and it may be significant here that the identity this ascribed-"people affected by cancer"-is not an especially oppressed or oppositional one, at least compared to other groups (for example, mentalhealth-service survivors) where user movements have been strong and their missions clear. The rather more ambivalent user identity in this field, and the heterogeneity of the involved users asked to enact it, thus seemed to require a degree of reinterpretation on the part of both parties involved. This reflects Davies et al.'s (2006) description of the experience of the individuals recruited by the National Institute for Health and Clinical Excellence to provide a 'citizen' perspective, which was defined too weakly to offer a guiding commonality or identity to those required to enact it. In this way, the findings emphasise Barnes et al.'s (2003, p.397) point, that "the importance of the micro processes through which official and lay discourses of the notion of 'representation' and legitimate participation are being negotiated suggests that the analysis of official discourse alone is insufficient to understand how 'the public' is constituted for public participation."

This might be taken to imply that the policy mandate will always be subject to distortion by those responsible for enacting it, to ensure fit with professional (or involved publics') conceptions of the appropriate role for public-participation initiatives. However, what is notable about the policy mandate for public and user involvement in current British policy is the breadth of forms and roles ascribed to it. As part of wider reforms introduced under Labour governments since 1997 aimed at 'modernizing' public services including the NHS, public participation has been accorded a variety of functions, relating, in Barnes et al.'s (2007) typology, to an 'empowered public', a 'consuming public', a 'stakeholder public' and a 'responsible public'. Furthermore, there is significant overlap and ambiguity in the ways public involvement is invoked in relation to these publics, so that at a policy level, multiple and complex rationales-and corresponding forms and publics-for participation coexist and interrelate (Martin, 2008). Thus rather than a clear shift in health-service governance with a coherently defined role and set of relationships, participation at a policy level "is a site in which tensions between different discourses and practices are played out" (Newman, 2001, p.139).

In this understanding, the versions of user involvement envisaged by staff and users in this study both find justification in policy rhetoric. Users constructed participation in terms of a 'stakeholder' discourse, in which their status as users (in some sense) of the service gave them a stake and role in its good governance, and to some extent in terms of an 'empowerment' discourse, in which they articulated an input on behalf of a disempowered public which challenged dominant professional modes of service delivery. Staff saw participation in more 'consumerist' terms, though this was a rather more deferential consumerism than that envisaged in policy, reworked in the same way as Newman and Vidler (2006, p.204) find professionals adopting the government's language of 'choice': through an "attempt to appropriate elements of consumerist discourse in order to secure $[. .$.$] professional goals." Each of these interpretations,$ with the corresponding notions of representativeness and legitimacy it implies, is acceptable and, indeed, finds support in the broad church of public-participation policy; furthermore, as we saw in the empirical section, the loose brief for participation set out by the DH and Macmillan in this case was accommodating of such interpretations.

Despite its emphasis on participation, then, British policy itself seems to facilitate rather an open approach to implementation, that can give rise to tensions such as those apparent here. In this sense, it differs interestingly from some other facets of Labour's NHS 'modernization' 
reforms. Where the rise of evidence-based medicine, for example, has seen a centralization of power and a scientific logic that has been little resisted by the medical profession (Harrison, 2002), state calls for public participation seem more ambivalent in character. They locate it at the centre of the 'new NHS' and place a statutory responsibility on organizations to do it, but offer multiple, ambiguous prescriptions about how, with little state management of processes and outcomes. Conflict over the remit of participation in practice of the kind seen here is a common result (cf. Rutter et al., 2004; Fudge et al., 2008). On a theoretical level, one might trace policy ambiguities back to the ambivalent status ascribed to the 'lay' public in social-theoretical accounts of late modernity, including those which have informed Labour's 'modernization' efforts, which for all their apparent calls for democratization, seem to retain a comparatively conventional view of the superiority of professional expertise over lay knowledge (Lash, 1994). On a more practical level, it may well be, as Salter (2004) argues, that the state is rather less interested in setting up an unambiguous mandate for public participation which might create new lines of accountability than in pursuing a more managerialist form of modernization, through projects such as evidencebased medicine, which centralizes power. Either way, this combination of multiplicitous participation policy and approaches to implementation that 'mandate without directing' leaves the role and remit of participation to dispersed, local negotiations, through the advancement of competing rationales for participation-each theoretically sophisticated and defensible, but neither given primacy by policy—but also through the deployment of positional power.

\section{Conclusion}

In common with previous findings, the role of representativeness and legitimacy claims in determining the course of user involvement in this study was evident. However, substantive as well as instrumental concerns were implicated in this negotiation, with professional staff apparently grappling with the extent to which a degree of representativeness, founded in users' typicality in relation to issues of universal interest to the wider public, could be ascribed to an atypical group of users. Users constructed their legitimacy somewhat differently, seeing their particularity of identity as a positive trait rather than an obstacle to representativeness. Both perspectives draw on constructions of representativeness that are contained within policy-level discourse about public participation, and the openness of the brief for user involvement put forward by the sponsors in this case-which demanded that staff recognize the legitimacy of participation, but did not specify the terms of that legitimacy-reflects the frequent vagueness with which these broad policy intentions are translated into practice. Consequently, implementation becomes a matter of negotiation, in which divergent rationales (whether adopted for instrumental or substantive reasons), reflecting different constructions of the relationship between the public, the state and professional expertise, coexist in tension, and are resolved pragmatically rather than on the basis of normative agreement or policy goals.

\section{References}

Barnes,M. (1999). Users as citizens: collective action and the local governance of welfare. Social Policy \& Administration, 33(1), 73-90.

Barnes,M., Newman,J., Knops,A., \& Sullivan,H. (2003). Constituting 'the public' in public participation. Public Administration, 81(2), 379-399.

Barnes,M., Newman,J., \& Sullivan,H. (2007). Power, participation and political renewal. Bristol: Policy Press.

Beresford,P., \& Campbell,J. (1994). Disabled people, service users, user involvement and representation. Disability \& Society, 9(3), 315-325.

Bowl,R. (1996). Involving service users in mental health services: social services departments and the National Health Service and Community Care Act 1990. Journal of Mental Health, 5(3), 287-303. 
Church,J., Saunders,D., Wanke,M., Pong,R., Spooner,C., \& Dorgan,M. (2002). Citizen participation in health decision-making: past experience and future prospects. Journal of Public Health Policy, 23(1), 12-32.

Contandriopoulos,D. (2004). A sociological perspective on public participation in health care. Social Science \& Medicine, 58(2), 321-330.

Contandriopoulos,D., Denis,J.-L., \& Langley,A. (2004). Defining the 'public' in a public healthcare system. Human Relations, 57(12), 1573-1596.

Crawford,M., Rutter,D., \& Thelwall,S. (2003). User involvement in change management: a review of the literature. London: NCCSDO.

Davies,C., Wetherell,M., \& Barnett,E. (2006). Citizens at the centre. Bristol: Policy Press.

Daykin,N., Sanidas,M., Tritter,J., Rimmer,J., \& Evans,S. (2004). Developing user involvement in a UK cancer network: professionals' and users' perspectives. Critical Public Health, 14(3), $277-$ 294.

Fudge,N., Wolfe,C.D.A., \& McKevitt,C. (2008). Assessing the promise of user involvement in health service development: ethnographic study. British Medical Journal, 336 313-317.

Harrison,S. (2002). New Labour, modernisation and the medical labour process. Journal of Social Policy, 31(3), 465-485.

Harrison,S., \& Mort,M. (1998). Which champions, which people? Public and user involvement in health care as a technology of legitimation. Social Policy \& Administration, 32(1), 60-70.

Lash,S. (1994). Expert systems or situated interpretation? Culture and institutions in disorganized capitalism. In U. Beck, A. Giddens, \& S. Lash (Eds.), Reflexive modernization (pp.198215). Stanford: Stanford University Press.

Martin,G.P. (2008). 'Ordinary people only': knowledge, representativeness, and the publics of public participation in healthcare. Sociology of Health and Illness, 30(1), 35-54.

Martin,G.P., Finn,R., \& Currie,G. (2007). National evaluation of NHS genetics service investments: emerging issues from the cancer genetics pilots. Familial Cancer, 6(2), 257-263.

Milewa,T. (1997). Community participation and health care priorities: reflections on policy, theatre and reality in Britain. Health Promotion International, 12(2), 161-168.

Milewa,T., Valentine,J., \& Calnan,M. (1999). Community participation and citizenship in British health care planning: narratives of power and involvement in the changing welfare state. Sociology of Health and Illness, 21(4), 445-465.

Newman,J. (2001). Modernising governance. London: Sage.

Newman,J., \& Vidler,E. (2006). Discriminating customers, responsible patients, empowered users: consumerism and the modernisation of health care. Journal of Social Policy, 35(2), 193209.

Rowe,R., \& Shepherd,M. (2002). Public participation in the new NHS: no closer to citizen control? Social Policy \& Administration, 36(3), 275-290.

Rutter,D., Manley,C., Weaver,T., Crawford,M.J., \& Fulop,N. (2004). Patients or partners? Case studies of user involvement in the planning and delivery of adult mental health services in London. Social Science \& Medicine, 58(10), 1973-1984.

Salter,B. (2004). The new politics of medicine. Basingstoke: Palgrave Macmillan.

Sanderson,I. (1999). Participation and democratic renewal: from 'instrumental' to 'communicative rationality'? Policy \& Politics, 27(3), 325-341.

Secretary of State for Health (2003). Our inheritance, our future: realising the potential of genetics in the NHS. London: The Stationery Office.

Tritter,J.Q., Barley,V., Daykin,N., Evans,S., McNeill,J., Rimmer,J., Sanidas,M., \& Turton,P. (2003). Divided care and the Third Way: user involvement in statutory and voluntary sector cancer services. Sociology of Health and Illness, 25(5), 429-456.

Williams,M. (2004). Discursive democracy and New Labour: five ways in which decision-makers manage citizen agendas in public participation initiatives. Sociological Research Online, 9(3). 